\title{
Sobre la localización geográfica de la qarya andalusí de Sobuerva (Šuburbal) y otras cuestiones
}

\author{
Concerning the Geographical Location of the Andalusi \\ qarya of Sobuerva (Shuburbal) and Other Questions
}

En este artículo se examina toda la documentación conocida para el estudio de la qarya de Sobuerva, citada en varias fuentes de época medieval y moderna. Diversos autores que nos antecedieron plantearon varias hipótesis sobre la ubicación de este lugar: Bormujos, Tomares y Guillena. En nuestro artículo intentamos desmontar tales propuestas para ofrecer una nueva tras haberse revisado una amalgama documental más rica y completa. Básicamente, nuestros argumentos pivotan sobre la lectura de importantes fuentes documentales, junto al uso de un Sistema de Información Geográfica (SIG). Este último responde a la necesidad de ir comprendiendo mejor la evolución territorial y fronteriza de una serie de actuales municipios del Aljarafe sevillano desde la Edad Media hasta la actualidad, siempre al calor de los datos históricos y arqueológicos disponi-

\author{
Luis-Gethsemaní Pérez-Aguilar \\ Universidad de Sevilla \\ Enrique Ruiz Prieto \\ Universidad de Sevilla \\ Álvaro Gómez Peña \\ Universidad de Sevilla \\ Jesús Rodríguez Mellado \\ Universidad de Sevilla \\ Gabriel Carvajal Mateos \\ Universidad de Sevilla
}

This paper aims to examine all known documentation for the study of the Muslim hamlet (al-qarya) of Sobuerva, cited ocasionally in Medieval and Modern Age sources. Several authors have proposed some hypotheses about the location of this place: Bormujos, Tomares and Guillena. In our paper we try to demonstrate the invalidity of such hypotheses and to offer a new one after the review of a more complete documentation. Basically, our arguments focus on the important documentary sources and the utilization of a Geographical Information System (GIS). The latter responds to the need to understand better the territorial and frontier evolution of a list of current towns of Aljarafe from the Middle Ages to the present, approaching to the available historical and archaeological evidences. The final result leads us to propose the location of the core of 
bles. El resultado final nos lleva a plantear la ubicación del núcleo de la qarya de Sobuerva en el actual municipio de Mairena del Aljarafe.

Palabras clave: Alquería; Sobuerva; Aljarafe; necrópolis de Cavaleri. the qarya of Sobuerva in the present municipality of Mairena del Aljarafe

Key words: Hamlet (al-qarya); Sobuerva; Aljarafe; Cemetery of Cavaleri.

\section{Introducción ${ }^{1}$}

Entre los años 2010 y 2011, a varios de los firmantes de este artículo se nos encomendó la tarea de investigar distintos aspectos relativos al pasado del Aljarafe sevillano, y más concretamente a aquella zona próxima al actual municipio de Tomares ${ }^{2}$. Uno de los temas que abordamos fue el relativo a la qarya de Sobuerva (Šuburbal), citada en las fuentes literarias de época musulmana y cristiana, y que ha sido ubicada en dicho pueblo por varios autores ${ }^{3}$, localización que queremos matizar más adelante al situar su núcleo en la antigua Tomares y en la actual Mairena del Aljarafe.

Antes de introducirnos en el tema desearíamos aclarar una cuestión previa. Existe un problema de disfunción semántica entre la palabra árabe qarya y la castellana "alquería» ${ }^{4}$, ya que ambas aluden a realidades poblacionales distintas. Mientras que el término castellano hace alusión a una especie de cortijo, el árabe se refiere, en palabras de V. Martínez Enamorado, a una unidad residencial agraria formada «por distintas viviendas que incluyen asimismo las áreas de trabajo a ellas

${ }^{1}$ Los autores quisiéramos dar las gracias a todas aquellas personas que de una forma u otra han contribuido a la realización del presente artículo, especialmente a las hermanas del Real Monasterio de San Clemente de Sevilla por habernos permitido acceder a su archivo, enriqueciendo de este modo los resultados de nuestro trabajo.

${ }^{2}$ Gómez, Pérez, y Ruiz, Historia de Tomares. De la Prehistoria Reciente a la Edad Contemporánea.

${ }^{3}$ Cf. los trabajos de González Jiménez, La repoblación de la zona de Sevilla durante el siglo XIV, p. 47; Herrera, El Aljarafe sevillano durante el Antiguo Régimen, p. 50, nota 52; Herrera, "De toponimia mínima aljarafeña", pp. 57-71; Domínguez y Vera, "Actividad Arqueológica Preventiva: Carta Arqueológica del término municipal de Tomares (Sevilla)", p. 3010.

${ }^{4}$ Esta misma idea ya ha sido sugerida por García Sanjuán, "La reciente investigación arqueológica sobre el territorio onubense durante el periodo andalusí: una revisión crítica", p. 24. 
vinculadas $\rangle^{5}$. Las comunidades campesinas ${ }^{6}$ que en ellas habitaban solían «asentarse bajo criterios clánicos o genealógicos» ${ }^{7}$. Para el presente artículo se emplean exclusivamente el término y su acepción en lengua árabe.

\section{2. Šuburbal musulmana}

Para aproximarnos históricamente a la entidad poblacional de Sobuerva tendremos que hacer uso de las referencias aportadas por Ibn 'Arabī de Murcia. Esta inclinación hacia los datos textuales viene en buena medida determinada por el desconocimiento arqueológico directo que se tiene sobre el sitio. Si bien creemos habernos acercado con mayor precisión que los que nos antecedieron a la ubicación geográfica del topónimo, como comentamos al principio de este estudio y como más adelante detallaremos, la exacerbada e intensa urbanización de los términos municipales del reborde oriental del Aljarafe sevillano en las últimas décadas impide de momento una constatación de nuestra hipótesis a pie de campo. Deberán ser futuras intervenciones las que apuntalen todavía más nuestra propuesta o permitan sustituirla por otra.

El primero de los problemas al que hemos tenido que hacer frente en nuestro estudio es precisamente el del origen del nombre. De las referencias más tempranas que se tienen sobre este topónimo se ha de nombrar la de la Takmila de Ibn al-Abbār ${ }^{8}$, donde se cita el gentilicio $a l-\breve{S}-b-r-\bar{l}$ para hacer mención al natural de $\breve{S}-b-r$. El apéndice de esta obra fue publicado por M. Alarcón y A. González'. En él se alude al šayj Abū l-Haŷŷâŷ Yūsuf ${ }^{10}$ como originario de este pueblo «al Este de Sevilla» ${ }^{11}$, al añadírsele a su nombre el gentilicio $a l-\breve{S}-b-r-b-r-\bar{l}$, es decir,

${ }^{5}$ Martínez Enamorado, Al-Andalus desde la periferia. La formación de una sociedad musulmana en tierras malagueñas (siglos VIII-IX), p. 639. Cf. Guichard, Al-Andalus frente a la conquista cristiana. Los musulmanes de Valencia (siglos XI-XIII), p. 247.

${ }^{6}$ Barceló, El sol que salió por occidente. Estudios sobre el Estado omeya en Al-Andalus, p. 27 y Guichard, Al-Andalus frente a la conquista, pp. 308-309.

7 Martínez Enamorado, Al-Andalus desde la periferia, p. 639.

${ }^{8}$ Ibn al-Abbār, al-Takmila li-kitāb al-Sila, p. 735, número 2083.

9 Alarcón y González, "Apéndice a la edición Codera de la «Tecmila» de Aben alAbbar".

${ }^{10}$ Bajo el término šayj se hace referencia a su cualidad de maestro sufí (Geoffroy, "Shaykh", t. IX, p. 410).

${ }_{11}$ Alarcón y González,“Apéndice a la edición Codera”, p. 590. 
«el de $\check{S}-b-r »$. La siguiente fuente en la que aparecen recogidos el topónimo y el gentilicio aquí estudiados es la Epistola de la Santidad de Ibn 'Arabi ${ }^{12}$. Este autor andalusí nació en Murcia en el año 1165, trasladándose su familia a Sevilla tras la llegada al poder de los almohades, cuando él apenas tenía ocho años de edad. En dicha ciudad se educó y creció, llegando «a desempeñar, muy pronto, el cargo de secretario de la Junta de la gobernación de esta capital» ${ }^{13}$. En esta obra habla de una serie de maestros sufíes que influyeron en su formación y en su pensamiento, entre los cuales aparece nuevamente citado el šayj Abū l-Haŷŷâŷ Yūsuf al-Šubarbulī. Del texto se desprende que el propio Ibn 'Arabī visitó y conocía de primera mano dicho lugar, de ahí que sea coherente darle mayor peso al nombre del sitio tal y como él lo recoge $(\breve{S}-b-r-b$ l) que al de la Takmila de Ibn al-Abbār $(\check{S}-b-r)$. Esto mismo ya fue observado en su momento por J. Oliver, quien llegó a decir que «nadie mejor que Ibn 'Arabī ha podido reproducir ese nombre, desde el momento en que se trataba de un lugar conocido por él como residencia de su maestro a quien iba a visitar allí con cierta frecuencia» ${ }^{14}$. En cuanto a su transliteración al castellano, nos parece más coherente la propuesta anotada por D. García Valverde ${ }^{15}$, Shubarbul, que la transmitida por M. Asín ${ }^{16}$, Subárbol, ya que la primera mantiene una mayor fidelidad respecto a la lengua árabe. Ello es así porque la consonante $/ s /$ equivale fonéticamente a la $/ \mathrm{ch} / \mathrm{francesa}^{17} \mathrm{o}$ a la $/ \mathrm{sh} /$ inglesa, sonido que en la lengua castellana se puede emular mediante las consonantes $/ s c h /$. Sin embargo, existen problemas en ambas en cuanto a la vocalización. En este sentido nos parece adecuada la propuesta de J. Oliver ${ }^{18}$ quien, comparando el término de Ibn 'Arabī con la alquería de Soborbal mencionada en el Repartimiento de Sevilla de la edición de Espinosa, entendió que «lo procedente será leer Šuburbal», es decir, Schuburbal.

12 Asín, Vida de santones andaluces. La «Epistola de la Santidad» de Ibn Arabî de Murcia, p. 78, 80 y 105; García Valverde, Los sufies de Andalucía, pp. 41, 74 y 225.

13 Sobh, Historia de la literatura árabe clásica, p. 1225.

14 Oliver, "«Soborbal» en el Aljarafe de Sevilla”, pp. 437-440. La consideración de Ibn 'Arabī como una fuente directa y de primer orden respecto a los maestros sufíes por él conocidos también ha sido esgrimida recientemente por Sánchez, Sufismo y poder en Marruecos, p. 49.

${ }^{15}$ García Valverde, Los sufies de Andalucía, p. 41.

${ }_{16}$ Asín, Vida de santones andaluces, pp. 78, 80 y 105.

${ }_{17}$ Maíllo, Vocabulario de Historia árabe e islámica, p. 13.

18 Oliver, "Soborbal", p. 438. 
La trasformación de Šuburbal a Soborbal podemos entenderla si tenemos en cuenta que la $/ \mathrm{s} /$ castellana fue una de las formas con las que se sustituía la $/ s \bar{s} n /$ árabe, y el cambio del sonido $/ u /$ a $/ o /$ se explica por el fenómeno de aperturismo vocálico.

¿Qué podemos decir sobre Šuburbal más allá del propio nombre del lugar? Fundamentalmente tres cosas. La primera de ellas se refiere a su realidad como qarya andalusí, mientras que la segunda trata sobre la vinculación de este asentamiento con el territorio dependiente de Hișn al-Faraŷ, una de las cabeceras del iqlìm de al-Šaraf. En tercer lugar se debe hacer referencia a la presencia en dicha entidad poblacional de un maestro sufí del que nos hablan las fuentes árabes de la época, Abū 1-Haŷŷâŷy Yūsuf. Pasemos a continuación a desarrollar y a analizar cada uno de estos aspectos.

\subsection{La qarya andalusí de Šuburbal}

Al venirnos dada la categoría de este asentamiento por los textos, el siguiente tema gira en torno a qué se refiere Ibn 'Arabī bajo el término qarya. A día de hoy conocemos dos traducciones de su obra al castellano y ambas parecen coincidir a la hora de entender que Šuburbal era un pueblo del Aljarafe ${ }^{19}$. Sin embargo, el término «pueblo» es aquí la traducción de la voz qarya, con lo que entramos en la problemática de si es o no la palabra «pueblo» la más adecuada de cara a su traducción debido a la polisemia observada en los distintos diccionarios de lengua árabe consultados ${ }^{20}$. Lo cierto es que Ibn 'Arabī en su obra da pocos datos sobre el lugar, pues su preocupación no era tanto el sitio sino la figura de su šayj. Nosotros a día de hoy somos incapaces de poder hacer siquiera una propuesta con fundamento sobre los rasgos morfológicos de este asentamiento rural. Empero, la ubicación geográfica del topónimo que hacemos podría constituir la base para posteriores estudios que permitan caracterizar arqueológicamente el lugar. No obstante, sí p. 41 .

19 Asín, Vida de santones andaluces, p. 78; García Valverde, Los sufies de Andalucía,

${ }^{20}$ La voz qarya, pl. qurà, significa aldea, caserío, pueblo (Corriente, Diccionario árabe-español, p. 266); pueblo; aldea; ciudad pequeña; comunidad rural (Cortés, Diccionario de árabe culto moderno Árabe-Español, p. 900); aldeas, pueblos y villas (Kaplanian, Alhambra, diccionario Árabe-Español/Español-Árabe, pp. 30, 570 y 726). 
podemos desmenuzar las líneas que Ibn 'Arabī dedicó a su maestro con el objetivo de rastrear algún tipo de información sobre Šuburbal.

Uno de los pasajes más fructíferos de la Epístola de la Santidad para el tema aquí abordado es el que sigue ${ }^{21}$ :

Kāna la-hu bi-dāri-hi bi-l-qaryati bi'run yastasqī min-hā li-wuḍ̄'i-hi; fa-ra'aynā bi-ȳānibi l-bi'ri šaŷarata zaytūn ${ }^{i n}$ qad 'alat wa-awraqat wa-hamalat-ŷismu-hā

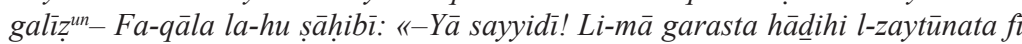
hā $\bar{d} \bar{a}$ l-mawdìi wa-dayyaqta bi-hā 'alà l-bi'ri?». Fa-ltafata ilay-nā wa-nazarawa-kāna qad inhanà zahru-hu min al-kibari-Fa-qāla: «-rubìtu fì hādihi l-dār min

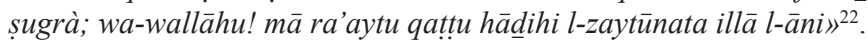

Tenía en su casa, en el pueblo, un pozo, del que sacaba agua para sus abluciones. Vimos al lado del pozo un aceituno, que había crecido [bastante], había echado [muchas] hojas, y se había llenado de frutos, siendo todo él muy grueso. Le dijo mi compañero: «—iMi señor! ¿Por qué plantaste este aceituno en este lugar, haciendo más estrecho [el acceso] hasta el pozo?» Se volvió hacia donde estábamos y observó [el árbol] -con su espalda inclinada por la vejez-y dijo: «-Me he criado en esta casa desde la niñez y, ipor Dios!, que no vi jamás este aceituno hasta ahora» ${ }^{23}$.

Por si alguien llegara a afirmar que el lugar donde vivía Abū 1Haŷŷâŷ cuando Ibn 'Arabī iba a visitarle era otro, y no Šuburbal, puede verse cómo en las distintas traducciones converge el hecho de que la casa donde ocurren las escenas que se relatan es en la que este maestro sufí se había criado desde niño. A través de este breve pasaje se constata la presencia de pozos en la zona a través de los cuales se accedía a las aguas del subsuelo. En este sentido debemos pensar que la propia formación litológica del Aljarafe fue propicia para el surgimiento de importantes acuíferos, cuyas aguas emergen a la superficie a través de manantiales o mediante pozos excavados en la roca. La referencia al aceituno nos pone sobre la pista de cómo la edilicia humana se inte-

${ }^{21}$ Las trascripciones a partir de ahora propuestas han sido llevadas a cabo a partir de la edición árabe de la Risālat al-quds de Ibn 'Arabī publicada por M. Asín Palacios en 1939. Tras las mismas se ofrecen traducciones al castellano llevadas a cabo por R. Mérida Fernández, licenciado en filología árabe por la Universidad de Sevilla, a quien agradecemos desde aquí su desinteresada colaboración. En dichas traducciones se anotan entre corchetes aclaraciones inexistentes en el texto original, pero útiles para su comprensión. A pie de página se referencian las respectivas traducciones ofrecidas por M. Asín y D. García Valverde. Agradecemos igualmente la ayuda ofrecida por la doctora en filología árabe I. Camarero Castellano en la revisión y las correcciones efectuadas en relación con las citadas transcripciones.

${ }^{22}$ Ibn 'Arabī, Risālat al-Quds (Biografías), pp. 20-21.

${ }^{23}$ Cf. Asín, Vida de santones andaluces, p. 82 y García Valverde, Los sufies de Andalucia, p. 43. 
graba en el paisaje de olivar. Sabido es a través de otros autores andalusíes, como al-Bakrī, que el Aljarafe sevillano ya destacaba por el predominio de este árbol entre las especies cultivadas ${ }^{24}$.

¿Dice algo Ibn 'Arabī sobre la casa de Abū 1-Ḥaŷŷâŷ en Šuburbal? Nuevamente nos encontramos con la pobreza descriptiva del texto, centrado más en el hombre que en su entorno. Sólo dos datos nos vienen dados sobre este asunto. Cuando se nos narra la historia de la gata de este maestro sufí se nos llega a presentar un pasaje en el que se dice que wa-kānat al-hirratu fi l-bayt al-äjir ${ }^{25}$ («estaba la gata en la última habitación» $)^{26}$, con lo que se deduce que la casa contaba con más de una, como viene a ser la norma en los espacios domésticos de ámbitos rurales de al-Andalus, pero tampoco se especifica el número exacto de las mismas. De otro lado, cuando Ibn 'Arabī trata de resaltar la bondad de su maestro, quien ofrecía lo poco que tuviera de comida a sus visitantes, nos relata un pasaje en el que él mismo se involucra, y en el que, ante una visita, su šayj le dijo: Yā bunayya! Anzil ilay-him al-miktala; fa-anzaltu-hu fa-lam aŷid fi-hi gayr mil' kaffin himmas ${ }^{\text {an27 }}$ («iOh, hijito mío! Bájales el cesto. Y yo lo bajé, pero no encontré en él más que un puñado de garbanzos») $)^{28}$. Además de desprenderse de este fragmento el posible cultivo de tales leguminosas en las huertas de este asentamiento rural, así como de testimoniarse el uso de cestería, tenemos que la casa de este maestro sufí podría haber tenido una segunda planta.

Pocas cosas más podemos decir de la Šuburbal musulmana de la mano de Ibn 'Arabī de Murcia. Aunque debemos considerar que en ella debió de existir una mezquita rural en función de la información que nos aportan documentos de época bajomedieval, y según los cuales sabemos que ésta fue donada en 1252 por el rey Alfonso X al cabildo catedralicio de Sevilla y arrendada por éste en 1305 a Pedro Martínez, alcalde de la capital hispalense ${ }^{29}$. También contamos con un plano de

${ }^{24}$ Al-Bakrī, Geografía de España (Kitāb al-Masālik wa-l-Mamālik), p. 33.

${ }^{25} \mathrm{Ibn}$ 'Arabī, Risālat al-quds, p. 21.

${ }^{26}$ Cf. Asín, Vida de santones andaluces, p. 83 y García Valverde, Los sufies de Andalucia, p. 44.

${ }_{27}$ Ibn 'Arabī, Risālat al-quds, p. 20.

${ }^{28}$ Cf. Asín, Vida de santones andaluces, p. 82 y García Valverde, Los sufies de Andalucia, p. 43.

${ }^{29}$ Montes, "El nacimiento del cabildo-catedral de Sevilla en el siglo XIII (12481285)", p. 426 y Ostos y Pardo, Documentos y notarios de Sevilla en el siglo XIV (13011350), pp. 102-103 y 415. 
Tomare $^{30}$, con su anejo de San Juan de Aznalfarache, realizado por M. de Ovando en 1628. En él aparece representado lo que quedaba de este sitio a comienzos del siglo XVII (ver figura 1). Su autor fue bastante detallista en general, tratándose de un plano muy preciso para el momento. Vemos cómo destaca lo que parece ser una torre, pero este documento tan tardío nos impide sostener de momento un posible origen andalusí para la misma. Lo que sí es altamente probable es que la necrópolis islámica de Cavaleri I, documentada arqueológicamente en 1991, estuviera vinculada a este asentamiento rural. El arqueólogo que la excavó no llegó a plantear dicha vinculación, sino que la asoció a otros yacimientos del entorno ${ }^{31}$. No obstante, el nombre de este lugar, realmente llamado Sovuelva de Cavaleri ${ }^{32}$, nos remite a la realidad poblacional aquí abordada, una entidad que, como más tarde veremos, se vio inmersa dentro de una dinámica de cambio que terminó diseccionándola a lo largo del tiempo en diversas partes. Una de ellas acabó siendo en el siglo XVIII propiedad de la familia de los Cavaleri, de origen italiano ${ }^{33}$. En el siglo XX se borra de la memoria colectiva el término Sovuelva, reconociéndose únicamente el topónimo como Cavaleri, de ahí que el excavador de la maqbara no hiciera tal asociación.

\subsection{El territorio de Hịsn al-Faraŷ, Šuburbal y otras qurà del Aljarafe sevillano}

En nuestro anterior trabajo, aunque afinamos más torpemente la ubicación del sitio, ya lo relacionamos por su cercanía con el entorno de Hiṣ̣n al-Faraŷ (San Juan de Aznalfarache, Sevilla) ${ }^{34}$, uno de los enclaves fortificados del cinturón defensivo de Išbīliya ${ }^{35}$. Este hiṣn, emplazado al S-O de Sevilla, cumplía una función doble. Se trataba de una avanzadilla de la defensa de la capital vía fluvial, pues desde ella

${ }^{30}$ Biblioteca Nacional de España: MR/43/044, 1002003040.

${ }^{31}$ Cf. Ramírez, "La necrópolis hispano-musulmana de Cavaleri. Mairena del Aljarafe, Sevilla", p. 534.

32 Arch. de la Dip. Prov. de Sevilla, leg. 535.

${ }^{33}$ Parias y Gamero, "Haciendas: las torres del paisaje olivarero sevillano", p. 133.

${ }^{34}$ Gómez, Pérez y Ruiz, Historia de Tomares, p. 147.

35 Valor, "Las fortificaciones medievales en la provincia de Sevilla", p. 192. 
se podía controlar la subida por el río Guadalquivir. De hecho, fue un lugar estratégico para la toma militar de Sevilla tanto en el período visigodo como posteriormente durante el avance cristiano. De otro lado, a través de Hiṣn al-Faraŷ el Estado ejercía su presencia o control en el iqlìm de al-Šaraf (Aljarafe), comarca de notable riqueza agrícola, y de la que Išbīliya debió de depender en buena parte para su abastecimiento. Hiṣn al-Faraŷ suponía el control del río Guadalquivir y de parte del Aljarafe. M. Valor, J. M ${ }^{\text {a }}$ Carabaza y A. I. Porras ${ }^{36}$ comentan que el territorio asociado a esta cabeza de distrito representaría aproximadamente un tercio del iqlìm de al-Šaraf. De ser ello así, Šuburbal quedaría sobradamente dentro de tal ámbito administrativo, y es con este hiṣn con el que la debemos relacionar, sin menoscabar la importancia que dentro de este ámbito de relaciones debió de jugar la cercana $m a-$ dìna. El término al-Šaraf es de por sí significativo, ya que en árabe hace alusión a una entidad topográfica elevada desde la que se dominan las vistas a partir de poniente ${ }^{37}$, siendo por ello relevante su reborde oriental de cara al control visual del territorio que circundaba a Išbīliya. A. Tahiri ${ }^{38}$, basándose en la rica información aportada por las fuentes escritas del momento, sostiene que este distrito quedaba delimitado por el Este por aquél otro dependiente directamente de Sevilla (iqlīm alMadīna), y algo más arriba por el de Țāliqa (Itálica). Hacia el Oeste el límite lo definiría el curso del Wādī l-Ṭalh, que el autor identifica con el Guadiamar, lindando con los aqālìm de Wibar o al-Burr (Huévar) y de Ṭalyāta o al-Bașal (Tejada). Dentro de al-Šaraf, y marcando el límite por el Norte, se hallaría Hịșn Qūra (Aznalcóllar), mientras que por el Sur sería el tránsito hacia las Marismas del Guadalquivir el que iría esbozando la frontera del distrito. Se trataba, por tanto, de uno de los aqālìm más extensos de la cora de Sevilla ${ }^{39}$, pudiendo llegar a alcanzar una superficie de $1.650 \mathrm{~km}^{2}$.

A. Tahiri nos comenta que el iqlìm de al-Šaraf se encontraba salpicado de numerosas qurà desde la época emiral hasta los momentos finales de al-Andalus, alcanzándose una máxima ocupación del territorio rural aljarafeño durante el califato en función de la información arro-

${ }^{36}$ Valor, Carabaza y Porras, "Espacio rural y territorio en el Aljarafe de Sevilla: Hịṣn al-Farâ̂", p. 354.

37 Tahiri, "El Aljarafe: Corona de Sevilla", p. 115.

38 Tahiri, "El Aljarafe", pp. 115-116.

39 Tahiri, Agricultura y poblamiento rural en Sevilla durante la época 'abâdî, p. 38. 
jada por autores como al-Mawwarī, donde se «baraja la cifra de doscientas veinte alquerías ${ }^{40}$. Una de estas qurà, como ya se ha dicho, fue la de Šuburbal, que según argumentaremos debió de encontrarse relativamente cercana a aquella otra de la que se hacen eco las fuentes, Muryāna al-gāfiqiyyīn (Mairena del Aljarafe), vinculada al linaje árabe de los Banū Gāfiq ${ }^{41}$. El mismo autor comenta cómo las fuentes árabes hacen alusión a otro tipo de entidades ocupacionales del mundo rural aljarafeño, tales como diversas cortijadas o maŷāšir, como por ejemplo el denominado Maŷšar Sayyid o el Maŷšar Balmīin ${ }^{42}$ El denso poblamiento del Aljarafe sevillano no sólo llamó a nivel cuantitativo la atención de los contemporáneos, sino que también lo hizo a nivel cualitativo. Así, al-Maqqarī llegó a escribir que tales poblaciones destacaban igualmente «por lo selecto de sus casas y por el celo que tenían de ellas por dentro y por fuera los vecinos, pues al encalarlas eran como estrellas en un firmamento de olivos» ${ }^{43}$. El suelo aljarafeño era considerado por los propios andalusíes de una alta calidad para el cultivo del olivar, aunque en él también tenían importante cabida otras especies como la higuera, la viña, el girasol y diferentes tipos de verduras y hortalizas, así como la producción de mie ${ }^{44}$. Sin embargo, fue el olivo el cultivo por excelencia de este territorio, haciéndose de ello eco las fuentes de la época ${ }^{45}$. La explotación olivarera del Aljarafe sevillano fue de gran relevancia dentro de al-Andalus, tratándose de una de las zonas de máxima productividad. Era tal la cantidad de aceite que se producía que éste no sólo se dedicaba para el comercio y el abastecimiento de la sociedad andalusí, sino que era exportado en barcos a otras regiones, tales como el Magreb y aquellas otras de Oriente ${ }^{46}$. Su importancia debió de ser capital igualmente para el Estado andalusí, ya que uno de los impuestos que se cobraba era aquél que recaía sobre la posesión de olivos, siendo recogido en aceite ${ }^{47}$. A. Tahiri nos informa igualmente sobre un impuesto especial que era recaudado en la región aljarafeña.

40 Tahiri, "El Aljarafe", p. 117.

${ }^{41}$ Tahiri, "El Aljarafe", p. 116.

42 Tahiri, Agricultura, p. 41 y Tahiri, "El Aljarafe", p. 118.

43 Tahiri, Agricultura, p. 39.

44 Tahiri, Agricultura, pp. 163-164, 183, 188, 191 у 193.

45 Tahiri, Agricultura, pp. 80-82.

46 Tahiri, Agricultura, pp. 80-82.

47 Tahiri, Agricultura, pp. 60, 61 y 142. 
Se trata de una tasa fiscal orientada a las provisiones reales (sult $\bar{a}$ niyya $)^{48}$. Así, entendiéndose lo estratégico del territorio en el plano defensivo y económico, podemos comprender por qué en determinados episodios aquellos que querían dañar los intereses del Estado andalusí atacaban indirectamente a la capital arrasando el Aljarafe, tal y como llegó a hacer Nāșir al-Dawla, señor de Niebla, en su enfrentamiento con al-Mu tadid de Sevilla durante la época taifa ${ }^{49}$.

Desde el punto de vista arqueológico ha podido constatarse hasta el momento la existencia de un total de 14 asentamientos rurales andalusíes próximos a Šuburbal que debieron de quedar igualmente vinculados a Ḥiṣn al-Faraŷ (ver figura 2) ${ }^{50}$, al encontrarse situados en las inmediaciones de dicho enclave de control territorial. Por tanto, desde esta cabecera de distrito el Estado andalusí controlaría fiscalmente a las distintas comunidades rurales del entorno ${ }^{51}$. Llama la atención el vacío poblacional observado al Suroeste del actual San Juan de Aznalfarache, hecho que quizás responda más a deficiencias documentales, debido a la profunda urbanización de tal sector, que a un vacío real de población. Si bien es cierto que las citadas actuaciones arqueológicas no han permitido analizar, grosso modo, la evolución del poblamiento a nivel cronológico, la distancia media entre los distintos asentamientos rurales varía aproximadamente entre 1 y $3 \mathrm{~km}$, con lo que la densidad ocupacional de este territorio fue notoria si la comparamos con otras zonas.

\section{3. Šuburbal: ¿un lugar de carácter místico?}

Una de las hipótesis que aquí barajamos sobre Šuburbal gira en torno a su posible carácter místico, ya que en este asentamiento andalusí del Aljarafe vivió, como ya se ha dicho, uno de los grandes maes-

48 Tahiri, Agricultura, pp. 61 y 142.

49 Tahiri, Agricultura, p. 194.

${ }^{50}$ A excepción de Muryāna al-gāfiqiyyìn, de cuya existencia tenemos constancia a partir de los datos literarios, el resto de asentamientos rurales andalusíes han sido documentados arqueológicamente en los siguientes trabajos: Escacena, "Yacimientos arqueológicos de época medieval en el flanco oriental del Aljarafe", pp. 579-587 y Guisado, Vera y Sardá, "Prospección Arqueológica Superficial y revisión de yacimientos catalogados en el término municipal de Gelves, Sevilla", pp. 3300-3305.

${ }^{51}$ Cf. Guichard, "Le problème des structures agraires en Al-Andalus avant la conquête chrétienne", pp.163-169. 
tros sufíes de al-Andalus. En la obra de Ibn 'Arabī se refleja claramente cómo Šuburbal no era una qarya ordinaria, sino un lugar al que acudían tanto iniciados en la vía sufí como otros maestros, y peregrinos que deseaban ser irradiados de la santidad del šayj ${ }^{52}$ e incluso ser curados de alguna enfermedad o dolencia ${ }^{53}$. Ello lo pone Ibn 'Arabī en boca de Abū l-Hâŷyâŷ cuando escribe: Yā bunayya! Fataha Allāhu 'alayya bāb qașada l-nāsu ilayya wa-ziyāratu-hum ${ }^{54}$ («iOh, hijito mío! Dios me ha abierto la puerta para que la gente se dirija a mí y me visite» $)^{55}$; o cuando narra la siguiente escena:

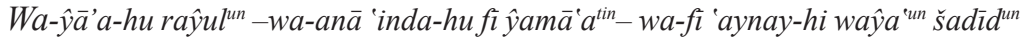
yașịhu min-hu mițla l-nafasā'i. Fa-dajala 'alay-hi-wa-qad šaqqa 'alà l-nāsi șiyāhu-hu-. Fa-isfarra waŷhu l-šayji wa-rta'ada wa-qala'a yada-hu l-mubārakata wa-wada'a-hà 'alà 'aynay-hi fa-sakana ${ }^{56}$.

Y le vino un hombre - estando yo reunido con él-que albergaba un dolor tan fuerte en sus ojos, que gritaba igual que una parturienta. Entonces [el enfermo], entró hacia [donde estaba el maestro] abriéndose paso entre la gente con sus gritos. El rostro del maestro palideció y se estremeció [al verlo]. Entonces sacó su mano bendecida y la puso sobre sus ojos [del enfermo] y [su dolor] mitigó [inmediatamente $]^{57}$.
\end{abstract}

Quizás el carácter místico de este lugar pudiera tener su reflejo en topónimos del entorno, tales como el del cercano Zaudín (Tomares, Sevilla), palabra que, según $\mathrm{R}$. Valencia ${ }^{58}$ debe de venir del árabe zaydin, término que deriva de alguna denominación con la raíz $s-^{-}-d$. Como ya hemos comentado en otro estudio ${ }^{59}$, dicha raíz se encuentra en palabras

${ }^{52}$ Cf. Alubudi, Sufismo y ascetismo, pp. 27, 44 y 47; Beneito, "Prólogo" a Historia del sufismo en al-Andalus. Maestros sufies de al-Andalus y el Magreb, pp. 10 y 12; Ernst, Sufismos: una introducción esencial a la filosofía y a la práctica de la tradición mística del Islam, pp. 92-93; González Rodríguez, "La presencia de Abū Madyan de Sevilla en el sufismo magrebí contemporáneo: el Mawādd del Šayj al-'Alāwī”, pp. 252-253 y 258 y Sánchez, Sufismo y poder, pp. 85-87.

${ }^{53}$ La importancia de la realización de actos milagrosos en el sufismo ha sido analizada desde un punto de vista antropológico por Ernst, Sufismos, pp. 90-91.

${ }^{54} \mathrm{Ibn}$ 'Arabī, Risālat al-quds, p. 20.

${ }_{55}$ Cf. Asín, Vida de santones andaluces, p. 81 y García Valverde, Los sufies de Andalucia, p. 42.

56 Ibn 'Arabī, Risālat al-quds, p. 21.

${ }^{57}$ Cf. Asín, Vida de santones andaluces, p. 84 y García Valverde, Los sufies de Andalucía, p. 44.

${ }_{58}$ Valencia, Sevilla musulmana hasta la caída del Califato: contribución a su estudio, pp. $472-473$.

${ }^{59}$ Gómez, Pérez y Ruiz, Historia de Tomares, pp. 150 y 152. 
que hacen referencia a la bienaventuranza o a la felicidad ( $s a^{\prime} \mathrm{i} d$, $s a^{\prime} d$, $s u$ ' $\bar{u} d, s a^{\prime} \bar{a} d a$ ), como si de un sitio de paso obligado se tratase para poder llegar a otro lugar donde encontrar tales virtudes. El carácter ritual de Zaudín podría quedar igualmente reforzado si tenemos en cuenta la presencia de un importante afloramiento de agua y el simbolismo de este elemento dentro de la religión islámica en general y de la mística sufí en particular ${ }^{60}$.

\section{Sobuerva cristiana}

Tras el repartimiento de la ciudad de Sevilla y de su alfoz, conocemos que las antiguas qurà del Aljarafe fueron fraccionadas para ser entregadas a los soldados cristianos $\mathrm{y}$, más tarde, a futuros pobladores. Sobuerva no debió de escapar a este fenómeno, puesto que fue adscrita como heredamiento ${ }^{61}$, es decir, «la cierta porción de terreno cultivado» (hereditas, fundus), a la vez que es una palabra sinónima de hacienda de campo, bienes raíces o posesiones de todo tipo ${ }^{62}$. Dicho de otro modo, eran «fracciones de una alquería» ${ }^{63}$. Nuestra hipótesis de trabajo pivota sobre el hecho de la existencia de casos concretos de heredades de Mairena de Aljarafe y de Bormujos que fueron parceladas entre 200 caballeros de linaje ${ }^{64}$. No obstante, la repoblación del alfoz de Sevilla no cumplió con las expectativas tenidas por la corona, en buena parte propiciadas por la venta de algunas tierras repartidas a sus contingentes, que marchaban nuevamente a sus lugares de origen abandonando las tierras asignadas. Además de ello, también repercutió en tal hecho el escaso atrevimiento de los hombres para poblar las zonas fronterizas junto a la retirada de cierta población islámica a tierras de dominio musulmán. Por consiguiente, muchos de los lugares antiguamente

${ }^{60}$ Gómez, Pérez y Ruiz, Historia de Tomares, pp. 160-161.

${ }^{61}$ Diól Soborbal, ques de término de Aznalfarache, en que ha cinquenta mill pies de olivar e de figueral, e por medida de tierra setecientas e sesenta arançadas (González, Repartimiento de Sevilla, vol. 2, p. 111). Este dato, si lo comparamos con la información del resto de heredamientos de la zona, permite comprobar que Sobuerva era por entonces uno de los más extensos del entorno en cuanto al número de aranzadas.

${ }^{62}$ Montes, El paisaje rural sevillano en la Baja Edad Media. Aproximación a su estudio a través de las propiedades territoriales del Cabildo-Catedral de Sevilla, p. 109.

${ }^{63}$ González, Repartimiento, vol. 1, p. 258.

${ }^{64}$ González, Repartimiento, vol. 2, pp. 208-210. 
poblados tras la conquista cristiana fueron abandonados. Fruto de este desconcierto fue la aparición de despoblados durante el siglo XIV, incluyéndose precisamente la propia Sobuerva ${ }^{65}$. Quizás todo este proceso no supuso la total ausencia de población en dicho lugar, pero sí una acusada disminución de la misma. Debemos tener en cuenta que el cabildo de Sevilla, en 1389, al menos poseía una propiedad en Sobuerva destinada al cultivo del olivo ${ }^{66}$, aunque en ningún momento se especifican las dimensiones del terruño ${ }^{67}$. Como ya se dijo anteriormente, se ha podido constatar cómo en 1252 el rey Alfonso X donó al cabildo catedralicio de Sevilla una serie de mezquitas del alfoz hispalense para beneficiar, entre otras cosas, a su hermano el infante don Felipe, arzobispo de Sevilla. Entre ellas se encontraba la mezquita de Sobuerva. A día de hoy desconocemos qué uso se le dio a la misma en tales fechas; sin embargo, la documentación conservada sí nos revela cómo casi medio siglo después este edificio fue arrendado por el cabildo al alcalde de la ciudad ${ }^{68}$.

Durante el siglo XV, asistimos a un fenómeno singular en el Aljarafe sevillano. Se trata de los movimientos migratorios endógenos de jornaleros temporales en busca de trabajo. Este hecho ha sido analizado por M. Borrero ${ }^{69}$, quien pone de manifiesto la importancia de tal dinamismo poblacional de cara a la comprensión de la transformación del territorio, cambiando sustancialmente los centros neurálgicos de la región con la desaparición de mitaciones (p. ej., la de San Juan de Aznalfarache) y, sobre todo, de propiedades rurales. Quizás fuera esta desaparición de las antiguas entidades poblacionales aljarafeñas, entre otros motivos, la causante de que en un momento impreciso entre fines del siglo XV y principios del XVI Tomares superase en número de habitantes a San Juan de Aznalfarache, con la que formaba un mismo municipio, pasando a ser la villa cabecera en detrimento de ésta ${ }^{70}$. Debió de ser en este contexto en el que Sobuerva pasó a depender de la villa de Tomares.

${ }^{65}$ González Jiménez, La repoblación, p. 47; Herrera, El Aljarafe, p. 317.

${ }_{66}$ Archivo Catedralicio de Sevilla, Mesa Capitular, Visitas de Heredades 1489 (9), 1389.

${ }^{67}$ Cf. Montes, El paisaje rural sevillano, pp. 69 y 213.

${ }^{68}$ Montes, "El nacimiento del cabildo", p. 426 y Ostos y Pardo, Documentos y notarios, pp. 102-103 y 415.

${ }_{69}$ Borrero, El mundo rural sevillano en el siglo XV: Aljarafe y Ribera, pp. 164-175.

70 Gómez, Pérez y Ruiz, Historia de Tomares, pp. 194 y 212; Herrera, "San Juan de Aznalfarache. A propósito de un libro de Pineda Novo", p. 296. 
En el Archivo del Real Monasterio de San Clemente (Sevilla) se ha podido consultar un bosquejo documental en el que se recopila información sobre las propiedades de dicho convento en tal lugar entre el siglo XVII y la primera mitad del XVIII ${ }^{71}$. En esta documentación se observa cómo la citada institución religiosa poseía una serie de propiedades en la zona, siendo la de Sobuerva una de ellas. La mayoría de las veces se alude a ésta situándola en el término de Tomares. Sin embargo, en ocasiones se hace referencia a Bormujos y a Palomares (que incluía por aquel entonces el actual término de Mairena del Aljarafe). Esto nos lleva a pensar sobre la posibilidad de que el territorio de la antigua alquería andalusí (de 760 aranzadas según el Libro de Repartimiento) fuese fraccionado en diversas parcelas, quedando algunas de ellas para esta fecha insertas en Tomares y otras en las citadas localidades. Las porciones de tierra que arrienda el monasterio son siempre muy inferiores a la cantidad que se repartió entre los conquistadores cristianos de la Baja Edad Media, con lo que ello es un indicio que refuerza todavía más el proceso de desmembración al que el territorio de la alquería se vio sometido, aunque desconocemos el momento exacto de dicho fraccionamiento. A partir de estos documentos sabemos igualmente que los cultivos predominantes eran el olivo y la vid, habiendo incluso menciones a molinos de aceite y a distintas casas en la zona, citándose cómo una de ellas disponía en su patio de un pozo que no contaba con brocal. De otro lado se hace referencia para esta zona al topónimo Las Mezquitas, una suerte de olivar y viña que lindaba con el camino que iba de Sobuerva a Zaudín. Dicho nombre de lugar pudo suponer la cristalización toponímica de la mezquita que conocemos a través de los documentos bajomedievales.

También para esta época contamos con un valiosísimo testimonio gráfico de 1628. Se trata del plano de Ovando, al que ya se ha hecho alusión, elaborado a petición de Gaspar de Guzmán, III Conde-Duque de Olivares, donde aparece el topónimo Soguerba Alqueria, situada al sureste de la actual residencia del club de golf Zaudín, junto al lugar de Zaudín alto. Como ya se dijo, el realismo del plano en cuanto a los sitios representados es bastante alto, hecho que hemos podido testimoniar al comparar lo que se dibuja de la villa de Tomares con los edificios

${ }^{71}$ Dichos documentos forman parte de los legajos 27, № 243 (Sección de Protocolos) y $81, N^{\circ} 85$ (Sección de Mayordomía). 
que aún hoy en día se conservan en el centro de este municipio sevillano $^{72}$. Si observamos lo que Ovando plasmó, podríamos hacernos una idea de lo que quedaba de este lugar a comienzos del siglo XVII: una torre y un par de construcciones (ver figura 1). Esta realidad probablemente no debió de corresponderse con la entidad del sitio durante la época islámica y bajomedieval, siendo factible la posibilidad de que otros edificios se desocuparan y terminaran arruinándose hasta desaparecer como tales. En este documento se constata de forma fehaciente lo que más arriba dijimos, ya que se puede deducir que el citado núcleo de Soguerba Alqueria se encontraba dentro de los límites territoriales de Tomares y su anejo de San Juan de Aznalfarache. Sin embargo, la documentación antes señalada nos permite certificar que, si bien el núcleo de la antigua qarya se hallaba por entonces en Tomares, había porciones de su antiguo territorio que se localizaban en los términos vecinos, de ahí que el topónimo trascendiera los límites de esta villa.

\section{La ubicación geográfica del topónimo}

Una de las aportaciones fundamentales de nuestro trabajo gira en torno a la cuestión de la ubicación geográfica del ámbito rural al que alude el topónimo. La Takmila de Ibn al-Abbār es nuevamente una fuente problemática y de poca fiabilidad para este asunto, ya que sitúa el lugar al Este de Sevilla. Sin embargo, J. Oliver ${ }^{73}$ enmendó tal error al comparar dicha información con aquella aportada por el Libro de Repartimiento de Sevilla, donde se dice que Alfonso X entregó en heredamiento una serie de «alcarias» entre las que se encontraba el sitio de Soborbal, perteneciente al término de Aznalfarache ${ }^{74}$, en el Aljarafe sevillano, al Oeste de la capital hispalense. Ante tal información, J. Oliver adjudicó dicho error a «una confusión entre $f \bar{a}$ ' y $q \bar{a} f$ sobre todo en textos orientales $»^{75}$ en relación a la voz al-Šaraf (Aljarafe). Asumida dicha observación, resulta más coherente la aportación que nos ofrecen las traducciones del relato de Ibn 'Arabī, quien llegó a decir

72 Gómez, Pérez y Ruiz, Historia de Tomares, pp. 220-221 y 227.

73 Oliver, "Soborbal", pp. 438-439.

74 Vid. nota 61.

75 Oliver, "Soborbal", p. 439. 
que se trataba de una qarya bi-l-Šarf 'alà farsaŷayn min Išbīliya ${ }^{76}$ («pueblo del Aljarafe, a dos parasangas de Sevilla») ${ }^{77}$. Basándose en esta reinterpretación, el mismo Oliver $^{78}$ fue el primero de los autores que realizó una propuesta sobre su ubicación situando el topónimo en la actual Bormujos (Sevilla). Para ello, una vez reorientada la búsqueda del Este al Oeste de Sevilla, se basó fundamentalmente en la información de un documento fechado en 1314 procedente del Archivo Catedralicio de Sevilla ${ }^{79}$ en el que se dice lo siguiente: «Marina Lorenzo da a la catedral de Sevilla tres tiendas que fueron mezquita en la calle de Francos, un olivar en Sobuerva, junto al camino de Santo Domingo, y otros bienes» ${ }^{80}$. Así, haciendo uso de la cartografía del momento, identificó dicho camino con la vereda real de Villamanrique. Sin embargo, dicho camino, si bien es cierto que pasa por Bormujos, también transcurre por Tomares, lo cual permite incluir a esta última localidad como posible área de ubicación del topónimo. De aquella localización defendida por Oliver han participado más recientemente otros autores ${ }^{81}$.

Con posterioridad a la interpretación dada por Oliver, M. González Jiménez ha situado Sobuerva en Tomares sin dar los motivos que le llevan a realizar tal afirmación ${ }^{82}$. Sí que lo ha hecho A. Herrera al situarla igualmente en este municipio basándose en la aparición en el plano de Ovando de la alquería denominada Soguerba, identificable con la Soborbal del Libro de Repartimiento de Sevilla ${ }^{83}$. Esta localización es la que hasta nuestros días ha gozado de mayor acuerdo entre los investigadores. Sin embargo, como expusimos al principio de este artículo, queremos someterla a algunas matizaciones que comentaremos posteriormente.

Por su parte, una propuesta bien diferente es la realizada por M. D. Gordón, quien ha intentado defender la localización de esta antigua

${ }^{76} \mathrm{Ibn}$ 'Arabī, Risālat al-quds, p. 19.

${ }^{77}$ Cf. Asín, Vida de santones andaluces, p. 78 y García Valverde, Los sufies de Andalucia, p. 41.

78 Oliver, "Soborbal", p. 439.

79 Archivo Catedralicio de Sevilla, 3-3-27.

${ }^{80}$ González, Repartimiento, vol. 2, p. 373.

81 Valencia, Sevilla musulmana, pp. 208-209 y Caballos, Escacena y Chaves, Arqueología en Laelia (Cerro de la Cabeza, Olivares, Sevilla), p. 55.

82 González Jiménez, La repoblación, p. 47.

${ }^{83}$ Herrera, El Aljarafe, p. 59 y Herrera, "De toponimia mínima aljarafeña", p. 59. 
qarya en Guillena basándose en cuatro criterios: el lingüístico, el geográfico, el textual y el arqueológico. Lingüísticamente, esta autora propone la relación de Sobuerva con el hidrónimo Borbolí, arroyo que nace entre las poblaciones de Guillena y Alcalá del Río, pasando por el también municipio sevillano de La Algaba hasta confluir con la Rivera de Huelva (antiguamente denominada de Buerva). Así, sugiere una conexión entre el topónimo Sobuerva y el hidrónimo Buerva, el cual aparece recogido en textos de época moderna. Por tanto, desde este planteamiento se defiende que el nombre de la qarya debe su origen al de la rivera. Al ser los aquí firmantes legos en materia de lingüística, no podemos refutar o avalar si la propuesta dada por Gordón se resiente en su posible evolución hidronímica, pero sí que podemos desmontar su hipótesis en los demás puntos en que se apoya. Así, geográficamente defiende que las dos parasangas de distancia a las que se encontraba Sobuerva de la capital hispalense, podrían corresponder con las dos parasangas de distancia a las que se encuentra La Algaba de Sevilla $^{84}$. Siguiendo la propuesta dada por J. Vallvé, que hace equivaler dichas dos parasangas con $11,1 \mathrm{~km}$ de nuestro sistema métrico actual ${ }^{85}$, la distancia entre ambas poblaciones resulta ser aproximadamente la misma, por lo que hasta aquí no hay nada incoherente. Lo que sí resulta curioso observar es que la autora se apoye en esta distancia relativa a La Algaba para posteriormente remitirse en todas las ocasiones a Guillena como lugar en el que ubicar Sobuerva (población a $25 \mathrm{~km}$ de Sevilla, más de cuatro parasangas). Por lo que respecta a su apoyatura textual, las referencias usadas por Gordón le hacen ver a Sobuerva como un lugar situado «a unos $11 \mathrm{~km}$ de Sevilla, en el Aljarafe, siendo una alquería habitada que formaba parte del término de Aznalfarache, y situada junto a un camino llamado de Santo Domingo» ${ }^{86}$. Así, obviando su ubicación en el Aljarafe, la autora le da mayor importancia al dato que sitúa a dicha alquería dentro del término de Aznalfarache, y hace caer dentro de esta jurisdicción territorial de manera errónea a las poblaciones de Guillena y La Algaba, las cuales formaban parte de la de Aznalcázar, por lo que una vez más su hipótesis se aleja de la realidad histórica. Por último, desde el punto de vista arqueológico, p. 347 .

84 Gordón, Toponimia sevillana ribera, sierra y aljarafe, p. 417.

85 Vallvé, "Notas de metrología hispano-árabe. El codo en la España musulmana",

${ }^{86}$ Gordón, Toponimia sevillana, p. 417. 
la autora defiende que el posible despoblado de Sobuerva se ubicaría cerca del Cortijo de la Torre de la Reina y de la Piedra Horadada, en Guillena, -lo que no cuadra con las dos parasangas de distancia con respecto a Sevilla-, donde se han encontrado restos de épocas prehistórica, romana, visigoda e incluso árabe ${ }^{87}$. Sin embargo, no es extraño que en innumerables sitios de Andalucía convivan restos de diversas épocas hasta en un mismo yacimiento, lo cual no es un dato que precisamente respalde su propuesta. Por último, un testimonio más en contra de esta hipótesis se desprende de la lista de topónimos reflejados en el Libro de Repartimiento antes y después de aparecer citada Sobornal, pues todos ellos apuntan hacia otra zona del Aljarafe ${ }^{88}$ : Parcina (¿actual Castilleja de la Cuesta?), Dunchuelas (actual Tomares), Lobanina (actual Tomares), Porçunes (actual Mairena del Aljarafe), Sobornal (antigua Tomares y actual Mairena del Aljarafe), Barannaniz (actual Castilleja de la Cuesta), Caçalla (actual Castilleja de la Cuesta), Triana (actual Sevilla), Goles (actual Sevilla), Dorbaniçale (ubicación desconocida), Quinicititalme (ubicación desconocida), Veres (ubicación desconocida), Çaudín (actual Tomares), Palmataçahahur (ubicación desconocida), Tomar (actual Tomares), etc. ${ }^{89}$.

Puestas en entredicho las anteriores hipótesis dadas hasta la fecha que sitúan a la qarya de Šuburbal en Bormujos y en Guillena, la primera por la escasez de datos que la apoyan y la segunda por la imprecisión de los argumentos, queremos matizar la idea que apunta su ubicación hacia el sur del municipio aljarafeño de Tomares. Es cierto, como ya se ha comentado anteriormente, que Sobuerva estuvo en el Aljarafe a unas 2 parasangas de Sevilla. Si seguimos, grosso modo, el trazado del antiguo camino a Villamanrique tenemos que la distancia de la capital en relación con el Sur del municipio tomareño varía aproximadamente entre 8,5 y $9 \mathrm{~km}$ (1,5 ó 1,6 parasangas). Esta hipótesis se ve también avalada por la aparición de Soguerba Alqueria dentro de los límites territoriales de este pueblo en el minucioso plano elaborado por Ovando en 1628. A todo ello tenemos que decir que, efectivamente,

${ }^{87}$ Gordón, Toponimia sevillana, pp. 417-418.

${ }^{88}$ Las diferentes variantes del Repartimiento de Sevilla recogen diversas versiones del mismo topónimo: Sobornal (E), Solorbal (AB), Sobrval (C) (González, Repartimiento, vol. 2, p. 111), Sobuerval (González, Repartimiento, vol. 2, p. 118), Sobernal (González, Repartimiento, vol. 2, p. 232) y Sobuerva (González, Repartimiento, vol. 2, p. 373).

${ }^{89}$ González, Repartimiento, vol. 2, p. 111. 
por estas fechas dicha entidad poblacional estuvo en Tomares, pero si contrastamos dichos datos con los límites municipales actuales vemos claramente cómo ya en 1891 el núcleo de Sobuerva se encontraba dentro de Mairena del Aljarafe (vid infra), población con la que linda al sur. En primer lugar, debemos tener en consideración las dos parasangas de distancia anotadas por Ibn 'Arabī, las cuales vienen a corresponderse aproximadamente con la distancia que hay entre Sevilla y la alquería de Sobuerva recogida en dicho plano (de 8,5 a $9 \mathrm{~km}$ ) si se realiza el trayecto por la vereda real de Villamanrique, camino principal para acceder desde Sevilla a Tomares en dirección a Bormujos y que tuvo que ser el antiguo camino de Santo Domingo que refleja el texto anteriormente citado. Este dato, evidentemente, viene a reforzar la hipótesis de que el topónimo aquí analizado se encontraba en la Tomares del primer cuarto del siglo XVII, pero como veremos, no en la actual. En segundo lugar, la presencia del topónimo Soguerba en el plano de 1628 guarda una estrecha relación con el de Sobuerva, pues la asimilación en el habla castellana entre los fonemas/bue/ y/güe/ es un hecho común tanto en el sur peninsular como en otros lugares.

El principal dato que nos habla del cambio de fronteras entre Tomares y Mairena es precisamente el límite que presenta el citado plano en la zona sur del municipio tomareño con su anejo de San Juan de Aznalfarache (ver figura 3). Si lo superponemos a la cartografía actual mediante un SIG a partir de la existencia de algunos edificios representados en el plano que todavía existen (las iglesias de Tomares y de San Juan de Aznalfarache, así como las haciendas de Zaudín Alto y Valdeparaíso, entre otras), podríamos apreciar varias cosas. La primera es una desviación del norte geográfico representado en la cartografía histórica. La segunda es un ligero error en la escala, existiendo con respecto a la realidad una variación de en torno a $200 \mathrm{~m}$ de distorsión en cada una de las medidas. Así, si la distancia entre dos puntos del plano fuera de $1.000 \mathrm{~m}$, la medida real diferiría de ésta en $200 \mathrm{~m}$. Aparte de estas apreciaciones, dicha superposición cartográfica nos ha permitido también apreciar una diferencia enorme entre los antiguos y los actuales límites del término municipal de Tomares en el área de Sobuerva, como venimos diciendo, cosa que no ocurre con las demás zonas a pesar de los pequeños errores de cálculo. En el mejor de los casos, si asumimos que el lugar de representación de Sobuerva en el plano de M. de Ovando tuviera un error de $200 \mathrm{~m}$, aplicando un buffer de esta medida 
como radio, seguiría estando su ubicación actualmente en Mairena del Aljarafe y no en Tomares. Sin embargo, en 1628 todavía seguía dicha entidad formando parte de este último municipio. Todos estos resultados se han podido realizar a partir de triangulaciones básicas. Es decir, si las mediciones entre edificios mantienen siempre este error de $200 \mathrm{~m}$, también las distancias entre éstos y Sobuerva deben de tener el mismo. Desafortunadamente, en nuestras pesquisas no hemos podido encontrar cuándo ocurrió el baile fronterizo, pero como mínimo sabemos que el núcleo de esta antigua qarya se encontraba ya dentro de Mairena del Aljarafe a finales del siglo XIX gracias al documento de separación de los términos municipales de Tomares y San Juan de Aznalfarache de 1891. La disputa entre ambos pueblos nos ha permitido obtener tres propuestas para el trazado de los límites de las dos poblaciones: de una parte el trazado realizado por Tomares, de otra el de San Juan y por último el practicado por un técnico nombrado para tal fin ante la falta de acuerdo. Dejemos que sea el propio técnico el que nos describa su recorrido:

Dentro de esta faja, hechas las computaciones debidas de las riquezas amillaradas y previa inspección ocular de las fincas comprendidas en ellas, se procedió a fijar la línea que había de servir de límite divisorio a los términos de ambos pueblos del modo siguiente.

Se tomó como punto de partida el centro de la Alcantarilla que existe sobre el cauce nombrado Madre Vieja del Río en la Carretera que desde Sevilla se dirige á la Puebla junto a Coria, continuando desde este punto en línea recta por el antiguo camino de Bollullos á la Cuesta llamada de la Mascareta. Se siguió por dicha cuesta hasta llegar al callejón que a su izquierda divide las dos suertes de olivar denominadas la del Olivar viejo y la cerca de la Hacienda del Carmen, conocida también por la Almendra. Se continuó por el referido callejón hasta el punto en que confluyen en la encrucijada de los cuatro callejones torciendo á la derecha por el antiguo camino de Mairena, hoy callejón perdido que atrabiesa la Hacienda de olivar de Esteban de Arones hasta llegar al camino de Sovuelva. Se continuó al salir de los olivares de Esteban de Arones por el límite divisorio de las hazas denominadas Alcantarilla y Sepaalta, y Santa Rita, quedando á la derecha las dos primeras y á la izquierda la tercera, saliendo á la haza de la Vitoria. De dicha haza de la Vitoria en el angulo que forma hacia la izquierda entre el Cuarto de Sovuelva de Cavaleri y los posillos de Santa Rita con la haza Sovuelva de Cartuja se segregaron por el referido lado izquierdo tres aranzadas de tierra tirando una línea que atravesando la citada haza de la Vitoria viniera a salir al padron divisorio ó camino que separa la referida haza de Sovuelva de Cartuja de la mencionada haza de la Vitoria. Se siguió por dicho camino á la derecha hasta el vallado que separa las tierras de Sovuelva de Cartuja de las de Sovuelva del Carmen, viniendo a salir al término de Mairena del Aljarafe. 
Toda la parte de la izquierda de la línea trazada se adjudicó al pueblo de San Juan de Aznalfarache, y la de la derecha de Tomares, representando el líquido imponible de las fincas correspondientes á cada uno de los dos pueblos conforme á los datos de amillaramiento $[\ldots]^{90}$.

Curiosamente, este topónimo no se menciona en la propuesta tomareña de deslinde, pero sí en la de San Juan de Aznalfarache:

Partiendo desde la Alcantarilla de la Madre vieja de la vega de Triana, límite del término de Sevilla, por la imediacion de la carretera hasta llegar a la Alcantarilla de la venta de Jurado, y siguiendo por la imediacion del camino que conduce a esta villa de Tomares hasta llegar a la suvida de la cuesta, tomando un padron que se encuentra a la izquierda que divide la haza de Manchon y el Olivar Viejo de la Hacienda del Carmen, hasta llegar a una callejon ó hijuela que sigue alrededor del camino vecinal que conduce a San Juan quedando a la derecha de la antes citada hijuela el olivar viejo y a la izquierda el olivar denominado Chaboya, que atrabezando dicho camino vecinal y siguiendo la hijuela hasta entrar y seguir un carril que atraviesa los olivos de la Hacienda de Esteban de Arones, hasta llegar a la portada de la mencionada Hacienda, siguiendo á la izquierda del antes dicho carril, y por los mismos olivares, y por junto a la era de esta Hacienda, hasta llegar a la portada del cacerio de San José, y desde la esquina de este cacerio, siguiendo á línea recta atrabezando Huerta y viña de dicho San José hasta llegar a la encina que se encuentra en los olivares de Doña Antonia Cavaleri, quedando á esta parte [la de Tomares] como seis o siete aranzadas de Huerta y viña siguiendo desde dicha encina á línea recta hasta concluir, donde se dividen los términos de Mairena del Aljarafe y estas villas.

[...] desde la Alcantarilla de la Madre Vieja del Rio limite del termino de Sevilla, hasta la haza de olivar llamada Sepaalta, la carretera de la Mascareta, que por dicha haza de Sepaalta se atrabezará, dejando de mi cabida para el termino de Tomares, seis ectareas ochenta y siete Hareas y sesenta y dos sentiareas, y para el de San Juan seis ectareas sesenta y seis Hareas y setenta y tres sentiareas, y siguiendo hasta el camino de Sobuelva por el que se continuara á la Haza del Granados que es el limite divisorio de Mairena del Aljarafe ${ }^{91}$.

Las numerosas menciones a Sovuelva/Sobuelva dejan patente que este topónimo, con ligeras variantes con respecto a momentos precedentes, seguía existiendo y además como denominador común a un conjunto de hazas denominadas de Cartuja, del Carmen y de Cavaleri, esta última citada en la propuesta tomareña como los olivares de Doña Antonia Cavaleri. Las citadas hazas debieron de ser fracciones del antiguo territorio de la qarya andalusí que mantuvieron a lo largo del tiempo el

90 Arch. de la Dip. Prov. de Sevilla, leg. 535.

91 Arch. de la Dip. Prov. de Sevilla, leg. 535. 
recuerdo toponomástico de dicho asentamiento. De igual modo, la fuerza de este nombre de lugar es tal a fines del siglo XIX que todavía seguía dando nombre al camino que conducía hasta estas fincas (ver figura 4). De nuevo los mapas vuelven a sumarse como testigos de esta realidad. La referencia a Sobuerva en este deslinde nos indica que una parte del agro de esa antigua qarya estaba dentro de Tomares en 1891. Para saber con cierta verosimilitud dónde habría estado ubicada ésta tenemos que volver a hacer alusión a la superposición del plano de 1628 con la cartografía actual y observar por dónde discurre la frontera de los municipios de Tomares y de San Juan de Aznalfarache con respecto a dichos topónimos. Podemos comprobar que en el deslinde de ambos municipios el núcleo edilicio de Sobuerva queda dentro del término municipal de Mairena del Aljarafe, si bien quedó fosilizado en la toponimia de la zona la existencia de, entre otras, una Sovuelva del Carmen que como podemos apreciar en la cartografía de 1946 queda dentro de Tomares (ver figura 4), siendo delimitada por su zona oriental por un camino de Sovuelva que cabría pensar que conduciría al antiguo núcleo del asentamiento. Esta sucesión de topónimos, que pueden resultar confusos para quien no conozca Tomares, puede verse en parte aclarada a través de este parcelario de 1946 que representa muchas de las fincas de Tomares en su límite con San Juan de Aznalfarache y con Mairena del Aljarafe. Así, desde la hacienda de La Cartuja (sobrenombre con el que se conocía a la de Esteban de Arones), lugares como Separta, La Victoria o Sovuelva del Carmen quedan bien reflejados en este plano. Como podemos apreciar, dicha Sovuelva del Carmen se encuentra dentro del término municipal de Tomares, no así las Sovuelvas de Cavaleri ni de Cartuja. En cuanto a la primera, la de Cavaleri, cercana a los «posillos» de Santa Rita, tuvo que encontrarse muy cerca de la necrópolis homónima comentada anteriormente, cuyo topónimo se ha fosilizado en una urbanización del norte de Mairena del Aljarafe. No así Santa Rita, que si bien también es el nombre de otra urbanización al norte de este mismo municipio, en un bosquejo planimétrico tomareño de 1873 daba nombre a una hacienda que habría quedado dentro del término municipal de San Juan de Aznalfarache tras su separación ${ }^{92}$.

\footnotetext{
92 Puede consultarse electrónicamente a través de la cartografía histórica del Instituto Cartográfico Andaluz con la signatura: Instituto Geográfico Nacional - AD ICA1989004220.
} 
Tras todo lo expuesto, sólo queda por decir que los aquí firmantes decidimos visitar el lugar por si había algún indicio arqueológico de la antigua qarya. La intensa urbanización del reborde oriental del Aljarafe sevillano era de por sí una dificultad previa para tal labor debido a la escasez de zonas no edificadas. De hecho, si quedasen restos del núcleo principal de la qarya, éstos se ubicarían bajo suelo urbano. Los pocos descampados existentes en los alrededores del área aquí analizada, próxima a la actual Ciudad Expo (Mairena del Aljarafe, Sevilla), ofrecían problemas de visibilidad debido a una gran densidad de vegetación, hecho que nos impidió percibir posibles evidencias arqueológicas en el terreno. A ello debemos sumar la inexistencia de actividades agrícolas recientes que faciliten el afloramiento en superficie de materiales arqueológicos. En nuestra visita a tales lugares pudimos constatar la presencia de cerámica común, de cronología indefinida, hecho que nos imposibilitó determinar aspecto alguno de forma clara. La zona se encuentra seriamente afectada por el trazado urbano. Por tanto, y como colofón a este trabajo, tendrán que ser futuros seguimientos e intervenciones arqueológicas las que permitan profundizar en el conocimiento de esta qarya citada en los textos, y sobre cuya localización hemos afinado manejando una documentación de diversa naturaleza y de distintas épocas. 


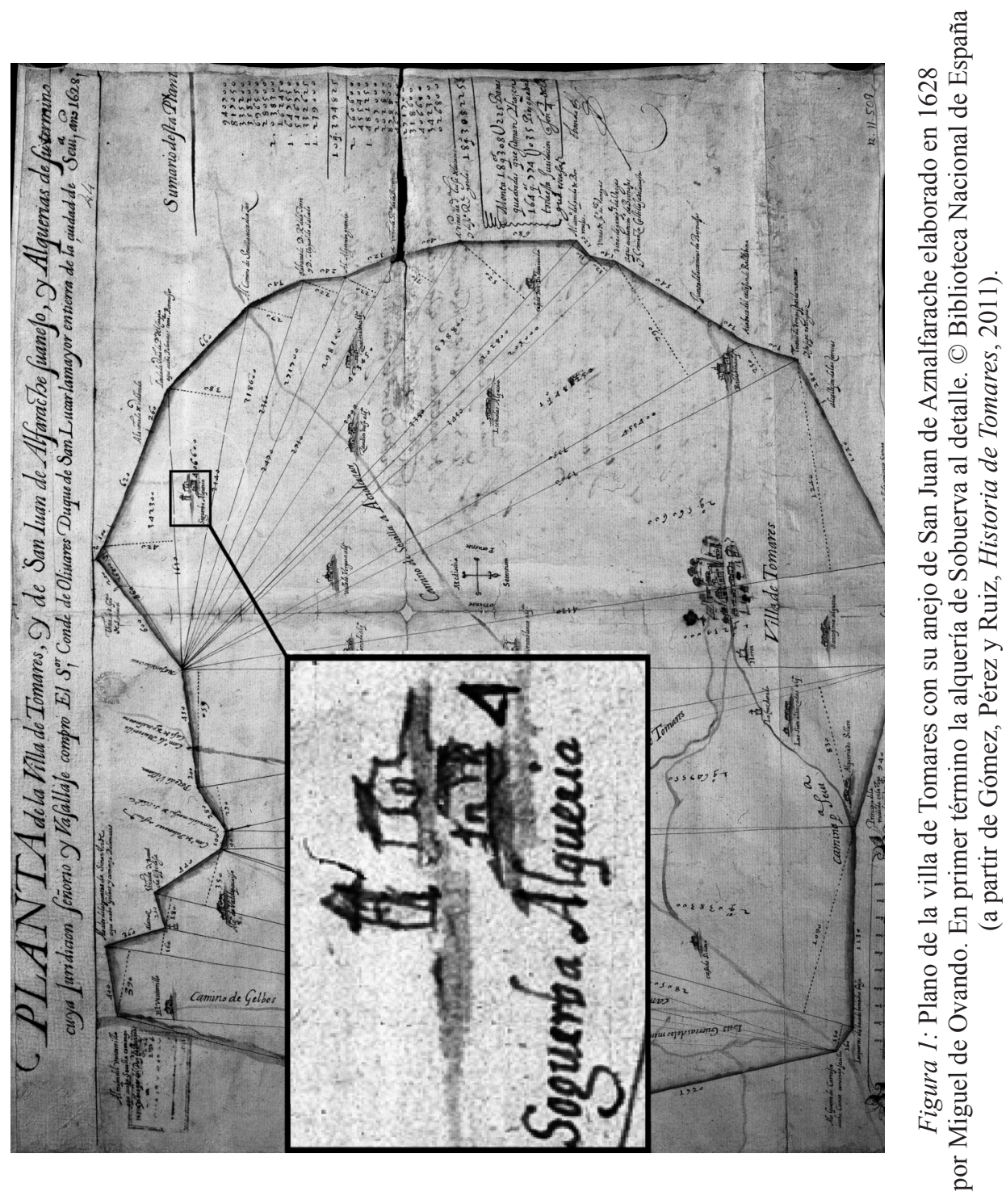




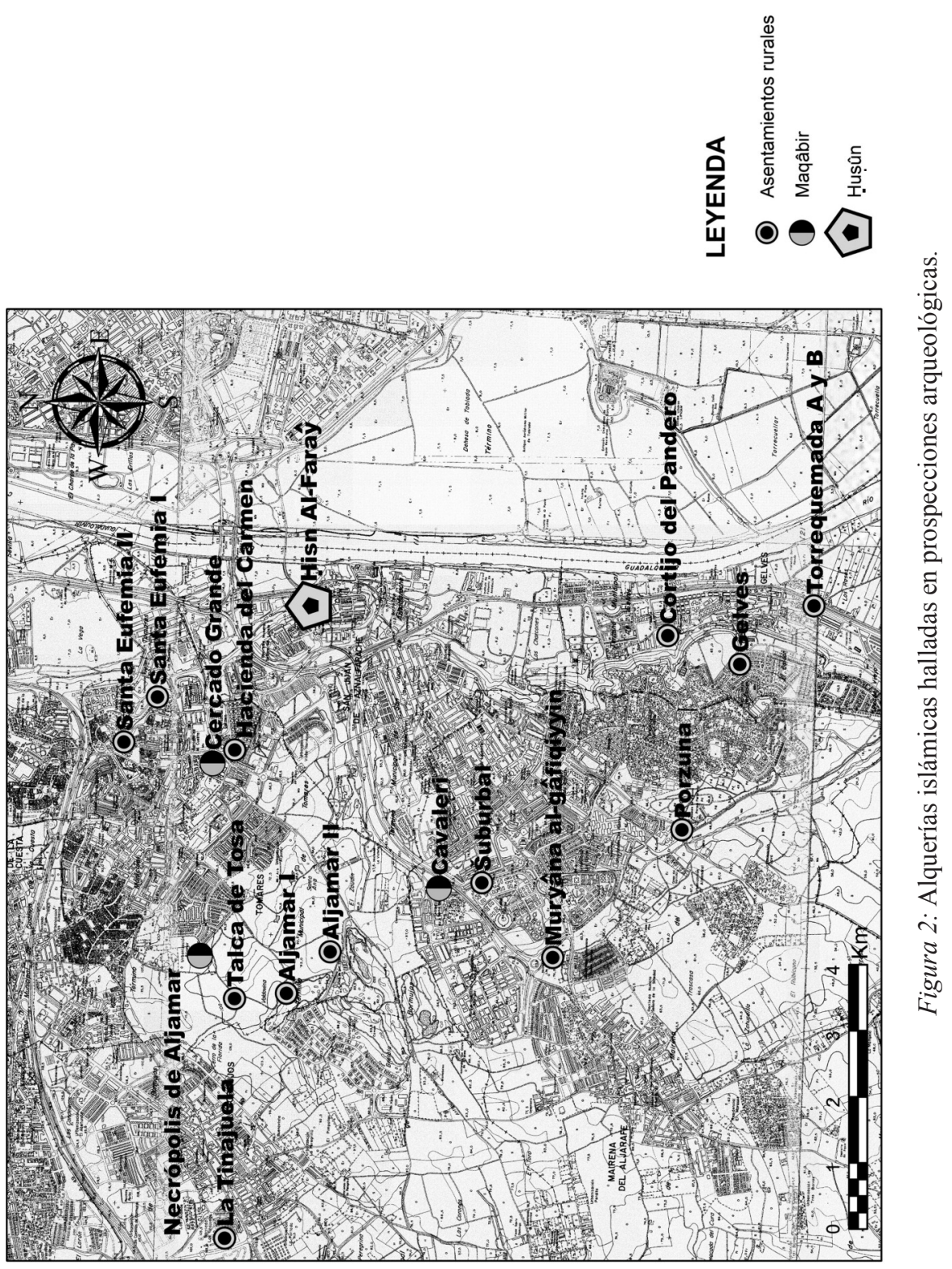




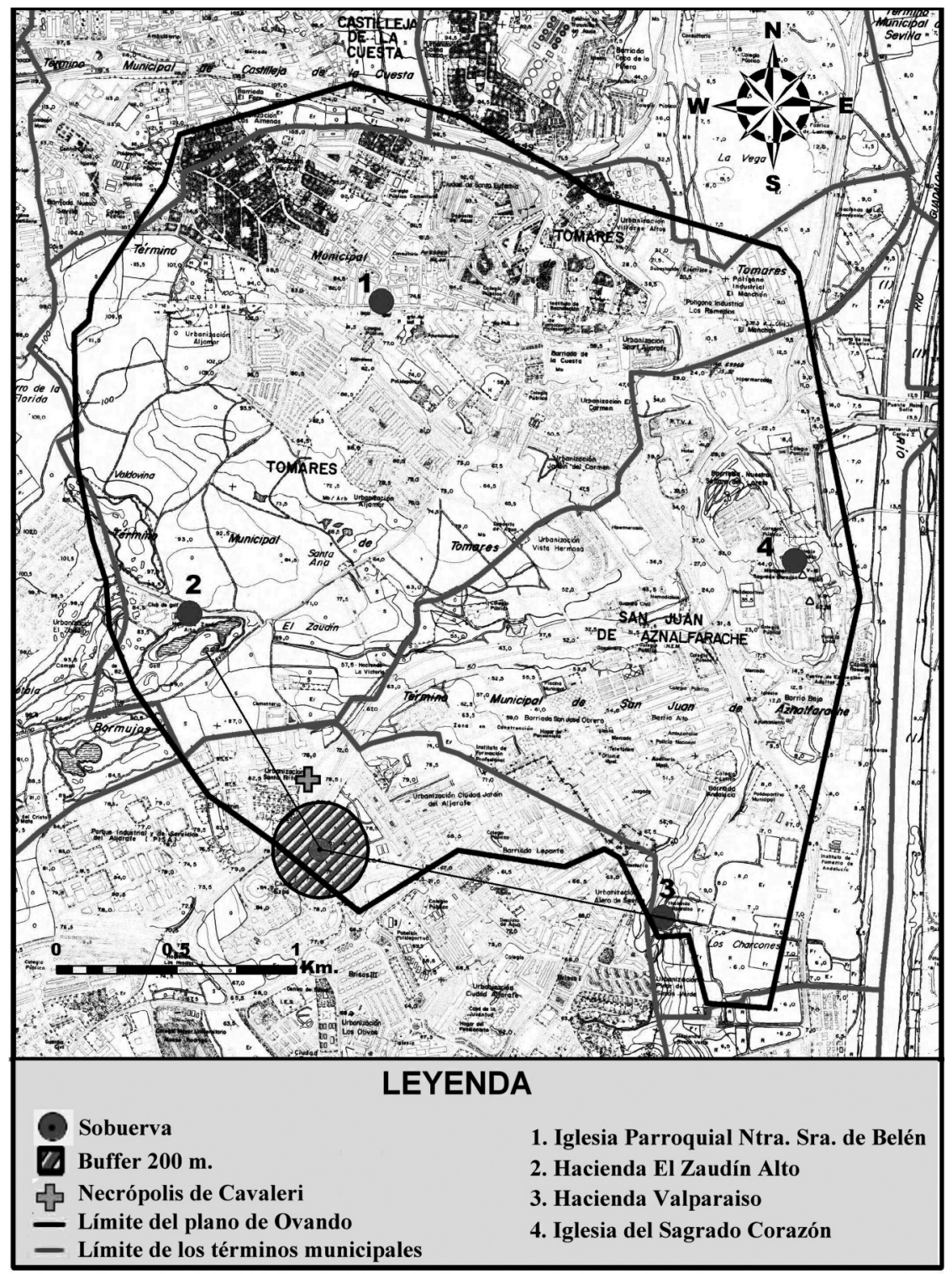

Figura 3: Situación hipotética de la alquería de Sobuerva. 


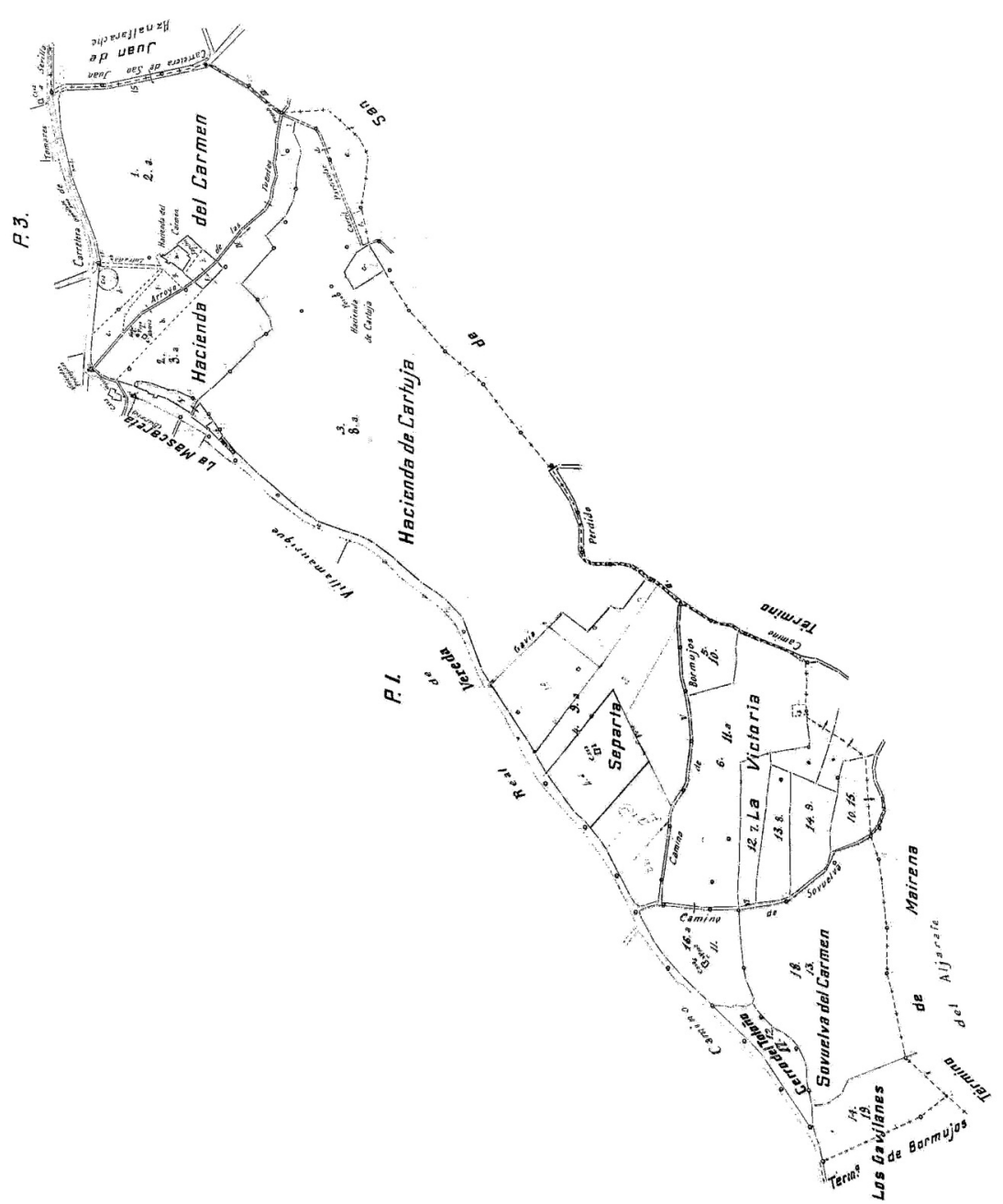

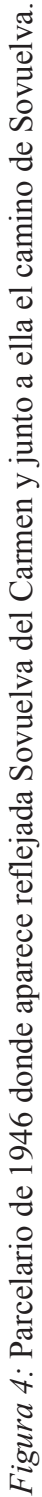




\section{Bibliografía}

Alarcón, Maximiliano y González, Ángel, “Apéndice a la edición Codera de la «Tecmila» de Aben al-Abbar”, en Miscelánea de Estudios y Textos Árabes, Madrid, Imprenta Ibérica-E. Maestre, 1915, pp. 414-611.

Alubudi, Jasim, Sufismo y ascetismo, Madrid, Vision Net, 2005.

Asín, Miguel, Vida de santones andaluces. La «Epístola de la Santidad» de Ibn Arabî de Murcia, Valladolid, Maxtor, 2005 (1933).

Al-Bakrī, Abū 'Ubayd, Geografía de España (Kitāb al-Masālik wa-l-Mamālik), Eliseo Vidal Beltrán (trad.), Zaragoza, Anubar Ediciones, 1982.

Barceló, Miquel, El sol que salió por occidente. Estudios sobre el Estado omeya en Al-Andalus, Valencia, Universidad, 2010.

Beneito, Pablo, "Prólogo", en A. González Costa y G. López Anguita (eds.), Historia del sufismo en al-Andalus. Maestros sufies de al-Andalus y el Magreb, Córdoba, Almuzara, 2009, pp. 7-14.

Borrero, Mercedes, El mundo rural sevillano en el siglo XV: Aljarafe y Ribera, Sevilla, Diputación Provincial, 1983.

Caballos, Antonio, Escacena, José Luis y Chaves, Francisca, Arqueología en Laelia (Cerro de la Cabeza, Olivares, Sevilla), Sevilla, Universidad y Ayuntamiento de Olivares, 2005.

Corriente, Federico, Diccionario árabe-español, Madrid, Instituto Hispano-Árabe de Cultura, 1977.

Cortés, Julio, Diccionario de árabe culto moderno Árabe-Español, Madrid, Gredos, 2004.

Domínguez, Enrique Luis y Vera, Alejandro, “Actividad Arqueológica Preventiva: Carta Arqueológica del término municipal de Tomares (Sevilla)", Anuario Arqueológico de Andalucía, 2005 (2011), pp. 3001-3018.

Ernst, Carl W., Sufismos: una introducción esencial a la filosofía y a la práctica de la tradición mística del Islam, Barcelona, Paidós Ibérica, 1999.

Escacena, José Luis, "Yacimientos arqueológicos de época medieval en el flanco oriental del Aljarafe", Actas del II Congreso de Arqueología Medieval Española, Madrid, Dirección General de Cultura, 1987, pp. 579-587.

García Sanjuán, Alejandro, "La reciente investigación arqueológica sobre el territorio onubense durante el periodo andalusí: una revisión crítica", Аrqueología y Territorio Medieval, 13, 2 (2006), pp. 7-31.

Geoffroy, Eric, "Shaykh”, en C.E. Bosworth, E. van Donzel, W.P. Heinrichs y G. Lecomte (eds.), Encyclopédie de l'Islam, Leiden, Brill, 1998, IX, p. 410.

Gómez, Álvaro, Pérez, Luis Gethsemaní y Ruiz, Enrique, Historia de Tomares. De la Prehistoria Reciente a la Edad Contemporánea, Tomares-Sevilla, Aconcagua Libros, 2011. 
González González, Julio, Repartimiento de Sevilla, Madrid, CSIC, 1951.

González Jiménez, Manuel, La repoblación de la zona de Sevilla durante el siglo $X I V$, Sevilla, Universidad, 2001.

González Rodríguez, Juan José, "La presencia de Abū Madyan de Sevilla en el sufismo magrebí contemporáneo: el Mawādd del Šayj al-'Alāwī”, en A. González Costa y G. López Anguita (eds.), Historia del sufismo en al-Andalus. Maestros sufies de al-Andalus y el Magreb, Córdoba, Almuzara, 2009, pp. 251-259.

Gordón, María Dolores, Toponimia sevillana ribera, sierra y aljarafe, Sevilla, Diputación Provincial y Fundación Luis Cernuda, 1995.

Guichard, Pierre, Al-Andalus frente a la conquista cristiana. Los musulmanes de Valencia (siglos XI-XIII), Madrid-Valencia, Ed. Biblioteca Nueva-Universitat de València, 2001.

Guichard, Pierre, "Le problème des structures agraries en Al-Andalus avant la conquête chrétienne", en E. Cabrera (coord.), Andalucía entre Oriente y Occidente (1236-1492). Actas del V Coloquio Internacional de Historia Medieval de Andalucía, Córdoba, Diputación Provincial, 1988, pp. 161-170.

Guisado, Fermín, Vera, Alejandro y Sardá, Diego, "Prospección Arqueológica Superficial y revisión de yacimientos catalogados en el término municipal de Gelves, Sevilla", Anuario Arqueológico de Andalucía, 2004, 1 (2010), pp. 3300-3305.

Herrera, Antonio, El Aljarafe sevillano durante el Antiguo Régimen, Sevilla, Diputación Provincial, 1980.

Herrera, Antonio, "San Juan de Aznalfarache. A propósito de un libro de Pineda Novo", Archivo Hispalense, LXIII, 192 (1980), pp. 293-299.

Herrera, Antonio, "De toponimia mínima aljarafeña", en Miscelánea de trabajos de investigación ofrecida al Dr. D. Vicente García de Diego López, Sevilla, Instituto de Bachillerato "San Isidoro", 1982, pp. 57-71.

Ibn al-Abbār, Muhammad, Al-Takmila li-kitāb al-Șila, Francisco Codera (ed.), Madrid, apud Michaelem Romero, 1886-89, Bibliotheca Arabico-Hispana, 5-6, 2 vols.

Ibn al-'Arabī, Los sufies de Andalucía, David García Valverde (trad.), Málaga, Editorial Sirio, 2007.

Ibn 'Arabī, Muḥammad, Risālat al-Quds (Biografias), Miguel Asín (ed.), Madrid-Granada, Escuela de Estudios Árabes de Madrid y Granada, 1939.

Kaplanian, Maurice G., Alhambra, diccionario Árabe-Español/Español-Árabe, Barcelona, Ramón Sopena, 1984.

Maíllo, Felipe, Vocabulario de Historia árabe e islámica, Madrid, Akal Ediciones, 1996.

Martínez Enamorado, Virgilio, Al-Andalus desde la periferia. La formación de una sociedad musulmana en tierras malagueñas (siglos VIII-IX), Málaga, Diputación, 2003. 
Montes, Isabel, "El nacimiento del cabildo-catedral de Sevilla en el siglo XIII (1248-1285)", Archivo hispalense, T. 77, № 234-236 (1994), pp. 417-458.

Montes, Isabel, El paisaje rural sevillano en la Baja Edad Media. Aproximación a su estudio a través de las propiedades territoriales del Cabildo-Catedral de Sevilla, Sevilla, Diputación Provincial, 1989.

Oliver, Jaime, “«Soborbal» en el Aljarafe de Sevilla", Al-Andalus, 24, 2 (1959), pp. 437-440.

Ostos, Pilar y Pardo, María Luisa, Documentos y notarios de Sevilla en el siglo XIV (1301-1350), Sevilla, Universidad, 2003.

Parias, María y Gamero, Mercedes, "Haciendas: las torres del paisaje olivarero sevillano", I Congreso de la Cultura del Olivo, Jaén, Instituto de Estudios Giennenses, 2007, pp. 121-138.

Ramírez, Francisco Oscar, "La necrópolis hispano-musulmana de Cavaleri. Mairena del Aljarafe, Sevilla", Anuario Arqueológico de Andalucía, 1991, 3 (1993), pp. 530-535.

Sánchez, Juan José, Sufismo y poder en Marruecos, Cádiz, Quorum editores, 2004.

Sobh, Mahmud, Historia de la literatura árabe clásica, Madrid, Cátedra, 2002.

Tahiri, Ahmed, Agricultura y poblamiento rural en Sevilla durante la época 'abâdî, Sevilla, Ayuntamiento, 2001.

Tahiri, Ahmed, "El Aljarafe: Corona de Sevilla", Documentos de Arquitectura y Patrimonio, 3-4 (2011), pp. 114-118.

Valencia, Rafael, Sevilla musulmana hasta la caída del Califato: contribución a su estudio, Madrid, Universidad Complutense, 1988.

Vallvé, Joaquín, "Notas de metrología hispano-árabe. El codo en la España musulmana", Al-Andalus, 41, 2 (1976), pp. 339-354.

Valor, Magdalena, "Las fortificaciones medievales en la provincia de Sevilla", en Actas del Congreso Internacional Fortificaciones en el entorno del Bajo Guadalquivir, Alcalá de Guadaira, Ayuntamiento, 2002, pp. 189-203.

Valor, Magdalena, Carabaza, Julia María y Porras, Ana Isabel, "Espacio rural y territorio en el Aljarafe de Sevilla: Hiṣn al-Farâ̂", en C. Trillo (ed.), Asentamientos rurales y territorio en el Mediterráneo medieval. Actas de las Terceras Jornadas de Arqueología Medieval, Granada, Athos-Pérgamos, 2002, pp. 337-372.

Recibido: $10 / 06 / 2012$

Aceptado: 12/06/2013 